\title{
THE EFFECTS OF TECTONIC RELEASE ON SHORT-PERIOD $P$ WAVES FROM NTS EXPLOSIONS
}

\author{
By Thorne Lay, Terry C. Wallace, and Don V. Helmberger
}

\begin{abstract}
The first cycle ( $a b$ amplitude) of teleseismic short-period $P$ waves from underground nuclear explosions at Pahute Mesa (NTS) show a systematic azimuthal amplitude pattern that can possibly be explained by tectonic release. The amplitudes vary by a factor of three, with diminished amplitudes being recorded at azimuths around $\mathrm{N}^{\circ} 5^{\circ} \mathrm{E}$. This azimuthal pattern has a strong $\sin (2 \phi)$ component and is observed, to varying degrees, for 25 Pahute Mesa events, but not for events at other sites within the NTS. Events that are known to have large tectonic release have more pronounced $\sin (2 \phi)$ amplitude variations. A synthesis of longperiod body and surface wave investigations of tectonic release for Pahute Mesa events shows that, in general, the nonisotropic radiation is equivalent to nearly vertical, right-lateral strike-slip faulting trending from $\mathrm{N}^{\circ} 0^{\circ} \mathrm{W}$ to due north. Longperiod $P$ waves at upper mantle distances demonstrate that there is a significant high-frequency component to the tectonic release. Using the long-period constraints on orientation, moment, and frequency content of the tectonic release, the expected short-period $P$ wave effects are predicted. For models in which the downgoing $P$ wave from the explosion triggers tectonic release within a few kilometers below the shot point, a factor of $\mathbf{2 . 5}$ amplitude variation with azimuth is predicted for the short-period $a b$ amplitudes, with the lowest amplitudes expected near $\mathrm{N} 25^{\circ} \mathrm{E}$. Rather subtle azimuthal variations in the waveforms are expected, particulary for downward propagating ruptures, which is consistent with the absence of strong variations in the data. The occurrence of the azimuthal pattern, albeit with varying strength, for all of the Pahute Mesa events suggests a tectonic release model in which the shatterzone surrounding the explosion cavity is extended preferentially downward by driving a distributed network of faults and joints underlying the Mesa several kilometers beneath the surface. In this model, all events could have a component of tectonic release which would reflect the regional stress regime, although there may be slight spatial and temporal variations in the tectonic release contribution. Some events may trigger slip on larger throughgoing faults as well. While it is shown that tectonic release can affect teleseismic short-period signals significantly, and may contribute to the Pahute Mesa amplitude pattern, other possible explanations are considered.
\end{abstract}

\section{INTRODUCTION}

For more than $20 \mathrm{yr}$, it has been known that underground nuclear explosions are commonly accompanied by substantial nonisotropic seismic radiation (Oliver et al., 1960; Press and Archambeau, 1962; Brune and Pomeroy, 1963; Aki, 1964). The existence of long-period transverse motion produced by explosions in both Love waves and $S H$ body waves (Nuttli, 1969; Hirasawa, 1971) provides the most direct evidence for the nonisotropic component. Relying principally on surface wave analysis, many early studies concluded that the explosions produce local release of preexisting tectonic stress; either by triggering nearby fault movement (Brune and Pomeroy, 1963; Aki, 1964; Aki and Tsai, 1972), or by stress relaxation around the spherical fracture zone created by the explosion (Press and Archambeau, 1962; Archambeau and Sammis, 1970; Archambeau, 1972; Lambert et al., 1972). At long periods, both mechanisms can be represented by an equivalent double-couple 
superimposed on the explosion; either directly (stress relaxation model) or somewhat lagged in space and time (fault model).

Despite the fact that the long-period surface wave analysis suffers from substantial ambiguity in determining the double-couple orientation and moment (Aki and Tsai, 1972), relatively little attention has been given to higher frequency signals. Aki et al. (1969) found that near-field tangential accelerograms indicate that event BENHAM triggered an earthquake a few seconds after the explosion, and Johnson et al. (1982) have performed moment tensor inversion of three-component strong motion data for the event HARZER showing that these can be interpreted as an explosion plus deviatoric source. The strongest evidence for teleseismic radiation of high-frequency energy from tectonic release was presented by Wallace et al. (1983). They demonstrated that $P$ waves recorded on long-period WWSSN instruments (with dominant signal periods of 2 to $3 \mathrm{sec}$ ) at upper mantle distances from Pahute Mesa explosions have clear $s P$ arrivals. Events which are within $4 \mathrm{~km}$ of a previous explosion usually have a substantially reduced $s P$ arrival. Analysis of $S H$ waves and regional $P_{n l}$ signals indicates that the tectonic release orientation is predominantly strike slip, although up to 10 per cent dip-slip contribution cannot be ruled out. For nearly pure strike-slip orientations, the time functions and moments required to produce the $s P$ arrivals in the long-period body waves were determined to have rupture durations less than $1 \mathrm{sec}$ and moments around $5.0 \times 10^{24}$ dyne-cm for events such as BOXCAR and GREELEY.

The implications of the long-period tectonic release models for short-period $P$ wave signals are investigated in this paper. There is considerable interest in the extent to which tectonic release can bias yield estimation techniques which rely on $m_{b}$ measurements. Murphy et al. (1983) have suggested that normal faulting tectonic release with a large stress drop of around 300 bars produced a systematic $m_{b}$ bias for the RULISON event of $\Delta m_{b} \sim 0.3$. Bache (1976) conducted a theoretical study of the potential effect of tectonic release on short-period amplitudes and waveforms, and concluded that the effect was negligible for vertical strike-slip orientations with moments and stress drops indicated by the early surface wave studies. We reinvestigate this problem in the light of the recent long-period body wave results along with a thorough investigation of the actual observations of teleseismic short-period $P$ waves from NTS explosions.

\section{Synthesis of Long-Period Studies of Tectonic Release}

In order to provide a context in which to analyze the short-period $P$-wave signals from NTS explosions, this section presents a synthesis of constraints on the nature of tectonic release inferred from long-period body and surface wave studies. Events at Pahute Mesa are emphasized as they are the most thoroughly documented.

Prior to 1974, several studies applied the inversion of Rayleigh wave amplitudes and Love/Rayleigh wave amplitude ratios to determine the relative sizes of the tectonic release double couples. The relative size of the nonisotropic component is indicated by estimates of the tectonic release moment, $M_{0}{ }^{d c}$, or by the $F$ factor (Toksöz et al., 1965) given by

$$
F \simeq \frac{3}{2} \frac{M_{0}{ }^{d c}}{M_{0}{ }^{\mathrm{exp}}}
$$

where the moment of the explosion is given by (Aki et al., 1974)

$$
M_{0}^{\exp }=4 \pi \rho \alpha^{2} \Psi_{\infty}
$$


The large number of parameters involved led most authors to constrain the mechanism of the double couple to be either vertical strike slip or pure dip slip, and then to invert for the azimuth and moment of the double couple. Aki and Tsai (1972) show that either type of mechanism can explain the surface wave data. The longperiod body wave observations discussed below support a predominantly strike-slip orientation, so the surface wave results found for such mechanisms are listed in Table 1. The parameters listed are the $F$ factor, or $M_{0}{ }^{d c}$, and the azimuths of the strike-slip fault planes. The mechanisms are all right lateral for the northerly trending fault plane. All events listed in Table 1 are from Pahute Mesa except for BILBY, FAULTLESS, and PILEDRIVER. For all cases, the azimuth of the easterly trending fault plane ranges from $70^{\circ}$ to $90^{\circ}$.

The orientation and moment of the tectonic release double couple can also be determined using long-period $S H$ observations. Because many of the available observations are at upper mantle distances, the moment estimates have substantial uncertainty, but often the orientation can be well-constrained. The results for strike-slip orientations found by Nuttli (1969), Hirasawa (1971), and Wallace et al. (1984) are included in Table 1. In general, they are very compatible with the surface wave results, which supports a strike-slip orientation of the tectonic release. Figure 1 presents a summary of the $S H$ observations for GREELEY. Below each observation, except near the radiation node, a synthetic $S H$ waveform or an analog $S H$ waveform observed for the 15 March 1979 Homestead Valley earthquake (JCT, DAL, and SHA) is shown (see Wallace et al., 1984 for details). The latter earthquake is a nearly vertical strike-slip event, and stations JCT, DAL, and SHA lie in the same portion of the $S H$ radiation pattern as for the tectonic release for GREELEY. The similarity of the entire $S H$ signals for the known strike-slip earthquake and the explosion $S H$ waves provides strong evidence that the tectonic release is predominantly strike-slip (see also Wallace et al., 1983). The $S H$ node for GREELEY clearly strikes close to $\mathrm{N} 25^{\circ} \mathrm{E}$, where the $F F C$ waveform is nodal in appearance. This orientation predicts that the direct $P$ wave from the tectonic release is opposite in polarity to the explosion $P$ arrival in the northeastern quadrant.

Further evidence of substantial strike-slip tectonic release is apparent in longperiod regional $P_{n l}$ waveforms of the Pahute Mesa events (Wallace et al., 1983). Events with large $P L$ 's (indicative of strike-slip) are GREELEY, BOXCAR, MUENSTER, and especially BENHAM. Assuming vertical strike-slip orientation, the average azimuth of the tectonic release $P$-wave nodal plane determined from $P_{n l}$ signals for these events is $\mathrm{N} 70^{\circ} \mathrm{E}$ (Wallace et al., 1983). The $P_{n l}$ waveforms for FAULTLESS, which was detonated $100 \mathrm{~km}$ north of Pahute Mesa, show little evidence for strike-slip energy release.

Wallace et al. (1983) demonstrated that long-period WWSSN $P$ waves at upper mantle distances from Pahute Mesa events show evidence of interference between the explosion-generated $P$ waves and the $s P$ arrival from the predominantly strikeslip tectonic release. The $s P$ arrivals are quite large and high frequency, with time function durations of less than $1 \mathrm{sec}$. The tectonic release orientations and moments indicated by the long-period $P$ waves are consistent with the $S H$ and surface wave results (Table 1). A systematic increase in the second upswing of the long-period $P$ waveform at station SHA with increasing $S V$ amplitude was detected. Since SHA is at an azimuth of $\mathrm{N} 97^{\circ} \mathrm{E}$, for which the $S V$ polarity for the strike-slip tectonic release arrival is the same as the $p S V$ polarity from the explosion, this suggests that the second upswing at SHA increases with increasing $F$ factor. This interpretation is supported by analysis of other stations at different ranges along the same azimuth from NTS (Wallace et al., 1983). 
TABLE 1

Long-Period Constraints on Tectonic Release for NTS Events

\begin{tabular}{ccccc}
\hline Event & $M_{0}^{d c *}$ & $\phi_{\mathrm{i}}(\mathrm{deg})$ & $\phi_{2}(\mathrm{deg})$ & Reference \\
\hline
\end{tabular}

Surface Wave Results

$\begin{array}{ll}\text { BILBY } & 0.50 \\ \text { BILBY } & 0.47 \\ \text { FAULTLESS } & 0.50 \\ \text { PILEDRIVER } & 3.2 \\ \text { GREELEY } & 1.6 \\ \text { BENHAM } & 0.85 \\ \text { HALFBEAK } & 0.67 \\ \text { BOXCAR } & 0.59 \\ \text { BENHAM } & \\ \text { BOXCAR } & \\ \text { BILBY } & \end{array}$

BILBY

\section{HALFBEAK \\ GREELEY \\ BOXCAR \\ BENHAM \\ GREELEY \\ ALMENDRO}

BENHAM

BOXCAR

CAMEMBERT

CHESHIRE

COLBY

ESTUARY

FONTINA

GREELEY

HALFBEAK

HANDLEY

INLET

JORUM

KASSERI

MAST

MUENSTER

PIPKIN

POOL

SCOTCH

STILTON

TYBO

$\begin{array}{lr} & -18 \\ & -20 \\ & -16 \\ & -20 \\ & -5 \\ & -15 \\ & -15 \\ & -14 \\ 2.5 & -6 \\ 1.25 & -12\end{array}$

72

70

74

70

85

75

75

76

84

0.25

76

$S H$ Wave Results

$\begin{array}{cll} & -28-3.5 & 62-86.5 \\ & -15-15 & 75-105 \\ 0.4-0.7 & -25 \pm 4 & 65 \pm 4 \\ 1.4-2.3 & -6 \pm 3 & 84 \pm 3 \\ & -2 \pm 3 & 88 \pm 3 \\ 1.0 & & \\ 5.6 & & \\ 1.4 & & \\ 1.4 & & \\ 0.7 & & \\ 0.8 & & \\ 0.7 & & \\ 2.2 & & \\ 3.1 & -20 & 70 \\ 1.0 & \end{array}$

1.0

2.4

0.3

0.5

2.0

0.5

3.2

0.2

0.2

0.3

0.1

0.3
Lambert et al., 1972

Toksöz and Kehrer, 1972

Toksöz and Kehrer, 1972

Toksöz and Kehrer, 1972

Toksöz and Kehrer, 1972

Toksöz and Kehrer, 1972

Toksöz and Kehrer, 1972

Toksöz and Kehrer, 1972

Aki and Tsai, 1972

Aki and Tsai, 1972

Aki and Tsai, 1972

Long-Period P-Wave Results

\begin{tabular}{lrrrl} 
GREELEY & 5.0 & -20 & 70 & Wallace et al., 1983 \\
FAULTLESS & $<1.7$ & & & Wallace et al., 1983 \\
BOXCAR & 5.0 & -20 & 70 & Wallace et al., 1983 \\
PAHUTE AVG. & & -20 & 70 & Wallace et al., 1983 \\
\hline
\end{tabular}

* Units are $10^{24}$ dyne-cm. 
Figure 2 presents additional evidence for the long-period $P$ waveform effects of increasing tectonic release. The long-period vertical components are shown for several Pahute Mesa events at stations SHA and SES $\left(\phi=N 14^{\circ} \mathrm{E}\right)$. Looking first at the SHA waveforms, it is apparent that $S V$ is enhanced for BENHAM and GREELEY relative to COLBY and HANDLEY, as is the second upswing in the $P$ waves. The high-frequency second upswing can be interpreted as an upward polarized $s P$ arrival for a vertical strike-slip double couple. Note the high-frequency content of the long-period $P$ waves. In order to produce such strong interference in

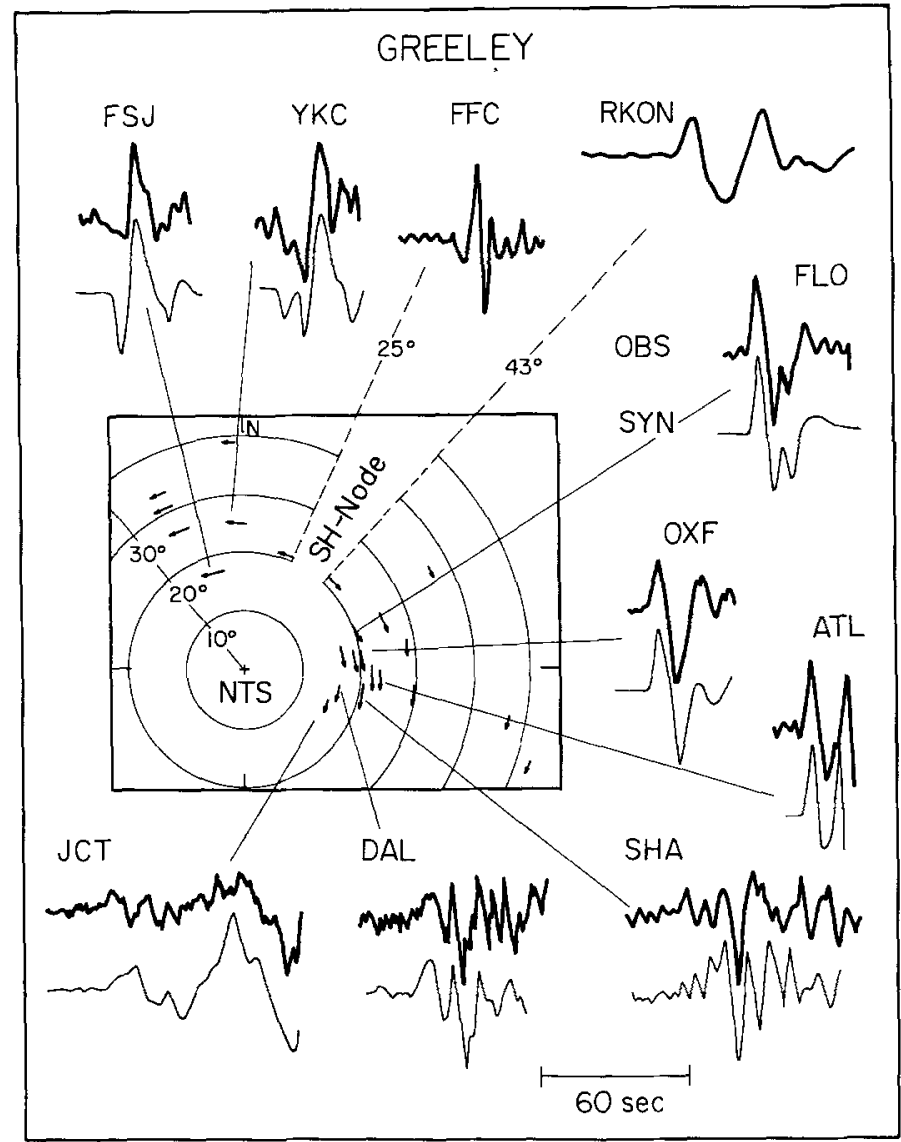

FIG. 1. $S H$ observations for GREELEY (top trace in each pair) compared with synthetic $S H$ waveforms or analog $S H$ observations from the Homestead Valley earthquake (JCT, DAL, and SHA). Note the clear reversal in polarity across an azimuth of $\mathrm{N} 25^{\circ} \mathrm{E}$. The actual $S H$ node is probably very close to $\mathrm{N} 25^{\circ} \mathrm{E}$ given the nodal waveform at FFC. Synthetics are not shown for the nodal stations FFC and the LRSM station RKON. The azimuthal polarity and amplitude plot is modified from Nuttli (1969).

these high-frequency signals, it is clear that both substantial moment and a short duration time function are necessary. The SES comparison is similar, with the high tectonic release events GREELEY and BENHAM having substantially different $P$ and $S V$ arrivals from those for low tectonic release events JORUM and HANDLEY. In this case, the $S V$ waveform changes polarity, as does the Rayleigh wave, between the events. Given the difference in azimuth, one would expect that the $s P$ arrival would have a downward polarity, producing a different interference effect than observed at SHA. This appears to be the case. Since the $S V$ radiation is nearer the 
loop direction for SES and opposite in polarity to the explosion arrival, the interference effects are stronger at SES for the $S V$ arrival as well, and both the $S V$ and Rayleigh wave arrivals are reversed for the large $F$ factor events.

Because the high-frequency $s P$ arrival apparent in the long-period $P$ waveforms has important implications for the short-period signals, the SHA waveforms were modeled for several large Pahute Mesa events. Figure 3 summarizes the results. Note that the second upswing is strong for GREELEY, MUENSTER, CAMEMBERT, and BENHAM, all of which have large tectonic release moments except for CAMEMBERT (Table 1). Because SHA is located at a distance of $24^{\circ}$, and because the high-frequency characteristics of the receiver function are unknown, it is

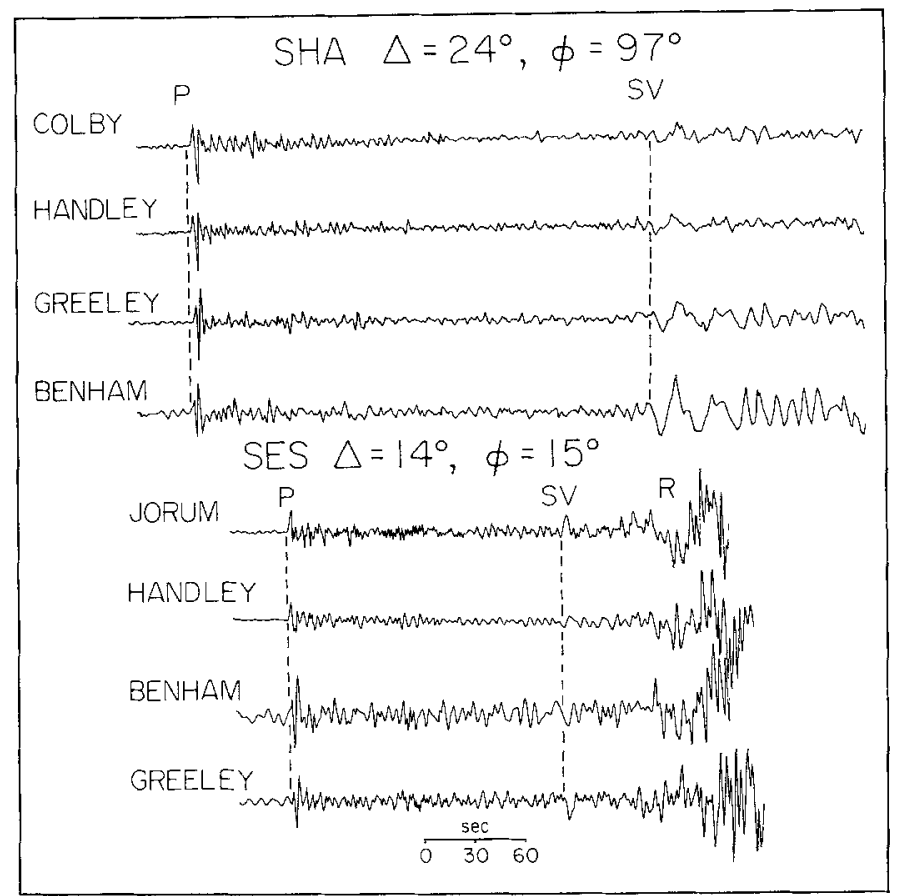

FIG. 2. Long-period vertical component recordings of several Pahute Mesa events from WWSSN station SHA (top) and CSN station SES (bottom). Note that at SHA, the second upswing of the $P$ wave increases with increasing $S V$ amplitude. This is interpreted as an increase in the size of an upward polarized $s P$ arrival from the strike-slip tectonic release with increasing tectonic release moment, because $S V$ interferes constructively at this azimuth. At SES, the long-period $P$ waves show more complicated variations, and the $S V$ and Rayleigh wave arrivals are reversed for the two high tectonic release events BENHAM and GREELEY. The differences between the GREELEY and JORUM waveforms shows that the $s P$ arrival changes polarity from that at $\mathrm{SHA}$ as does the $S V$ arrival.

difficult to model these records quantitatively. We have adopted a simplified procedure of determining the relative amounts of tectonic release contribution needed to produce the observed variations in the $P$ waveforms. Since COLBY is known to be a low tectonic release event from other lines of evidence, we have used it as a reference signal. We then sought to model the other waveforms by adding the response for a double couple to the COLBY observation, after scaling the COLBY amplitude to account for the difference in yield of the events. Since COLBY does appear to have some tectonic release, this procedure can only estimate the relative amount present from event to event. The double-couple contributions were generated for upper mantle model $T 7$ (Burdick and Helmberger, 1978). The time 
function used for the tectonic release component is a 0.50 -sec duration trapezoid $(0.15,0.20$, and 0.15$)$. Such a high-frequency source was found for other upper mantle long-period $P$-wave observations by Wallace et al. (1983). The other stations they used indicate that the ratio of dip-slip to strike-slip contribution is probably not more than $1: 5$, so we constrained the double couple to be vertical strike slip. The moments of the double couple required to match each waveform are shown in Figure 3. The moments needed to match the waveforms can be reduced by allowing even small components of dip slip. The double couple is lagged by $1 \mathrm{sec}$ relative to the explosion arrival. We did not attempt to model the waveforms for HALFBEAK

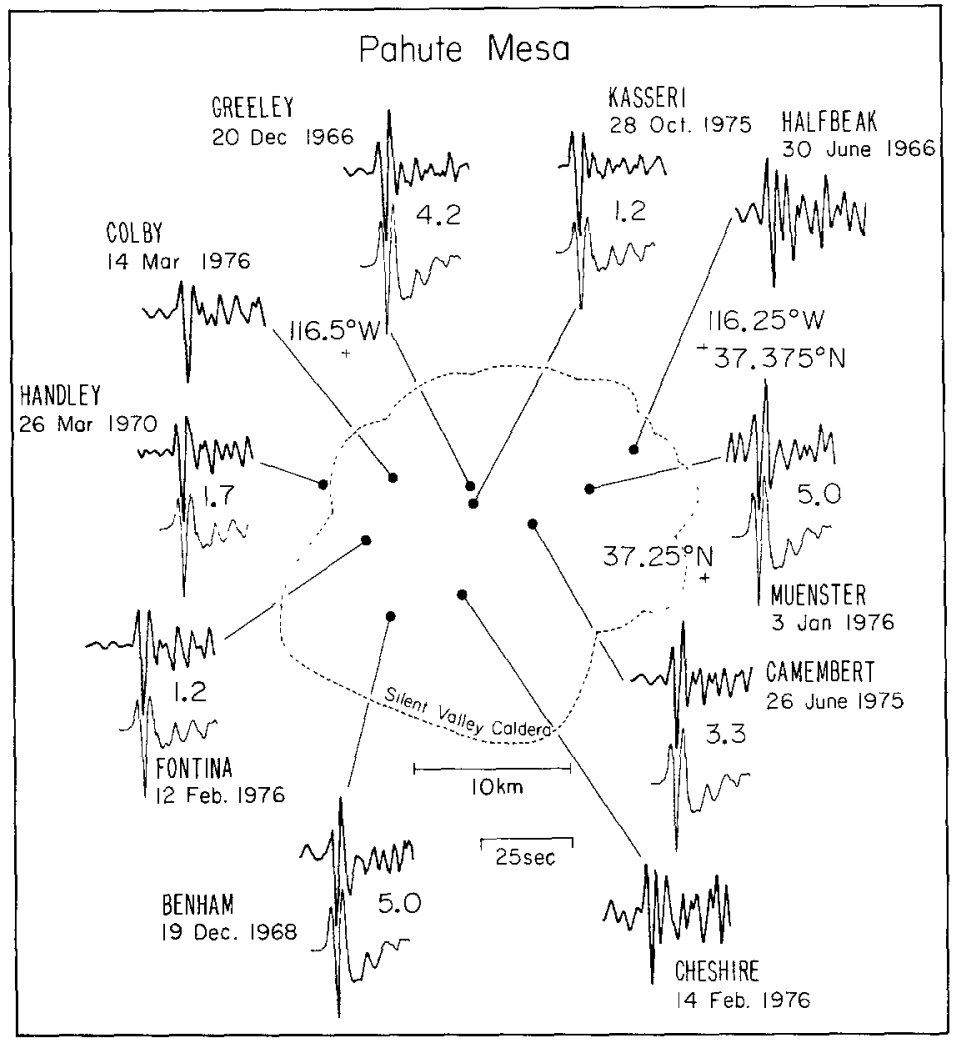

FIG. 3. Long-period $P$ waveforms observed at WWSSN station SHA for various Pahute Mesa events (top trace) compared with synthetics produced by adding the COLBY waveform (suitably scaled for yield) to the response for a vertical strike-slip double-couple at $3-\mathrm{km}$ depth (bottom trace). The moment of the double couple required to match the second upswing in the $P$ waveform for each event is indicated, with the units being $10^{24}$ dyne-cm. The overshoot of the second upswing increases with increasing tectonic release contribution as was indicated by Wallace et al. (1983).

and CHESHIRE, which are more complicated than those of the other events. The short-period signals for the latter two events, as well as for MUENSTER, differ from the other Pahute Mesa events. Due to the uncertainty in the upper mantle structure (SHA is near the crossover distance for the $670-\mathrm{km}$ discontinuity), the absolute moment estimates are not considered reliable, but the relative tectonic release contribution appears to be resolvable.

\section{Teleseismic Short-Period Data}

The long-period results summarized previously indicate that the tectonic release accompanying most Pahute Mesa events is characterized by predominantly right- 
lateral vertical strike-slip faulting trending $\mathrm{N} 20^{\circ} \mathrm{W}$, with substantial high-frequency radiation. Keeping this in mind, we now consider the teleseismic short-period $P$ wave observations for a large number of Pahute Mesa events, many of which are too small for any detailed analysis of long-period signals. Figure 4 shows the locations of the 25 Pahute Mesa events considered, and the azimuthal distribution of WWSSN and CSN stations in the distance range $25^{\circ}$ to $95^{\circ}$ for which the
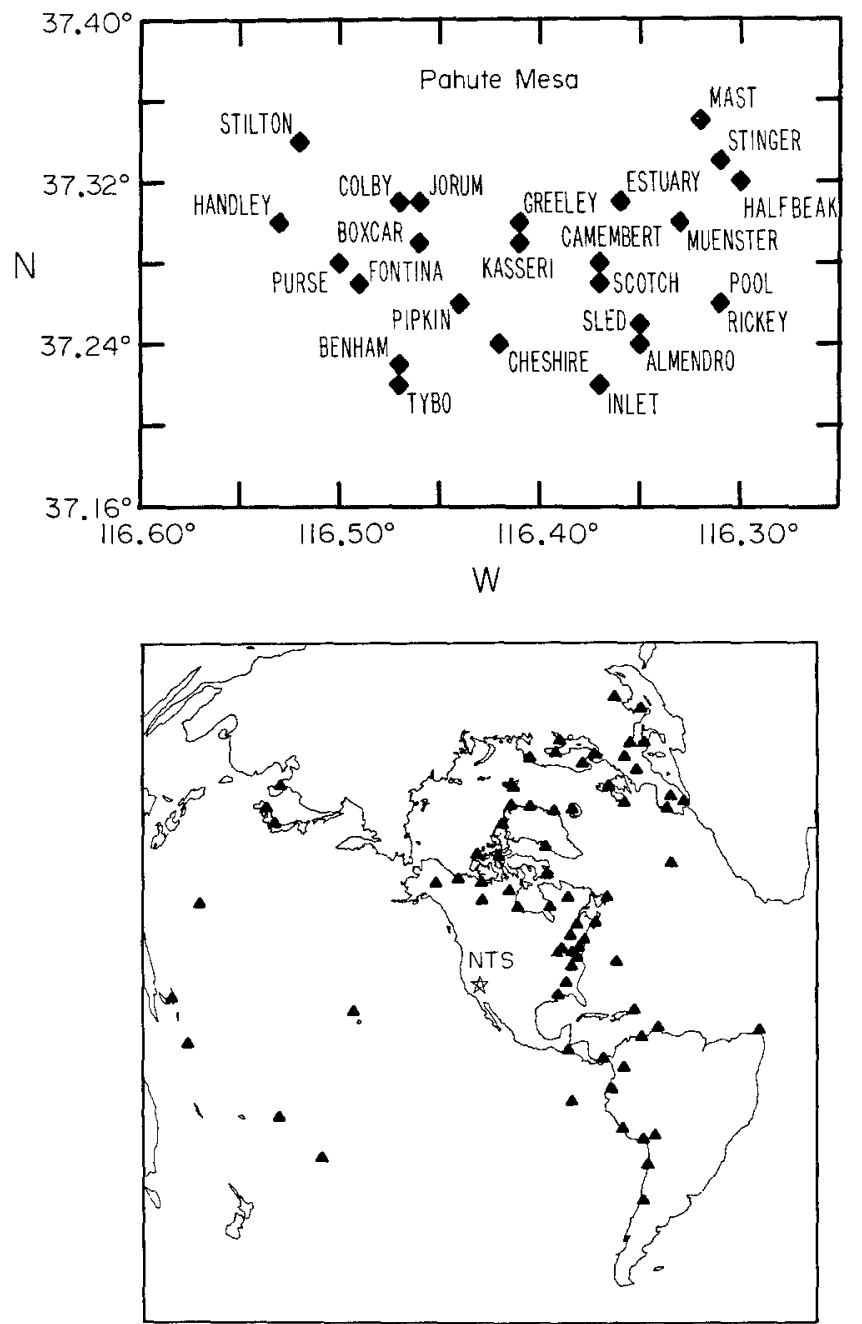

FIG. 4. (Top) Base map showing the locations of the 25 Pahute Mesa explosions for which the teleseismic short-period $P$-wave amplitudes are measured. (Bottom) The distribution of the 71 WWSSN and CSN stations in the distance range $25^{\circ}$ to $95^{\circ}$ from NTS at which the short-period amplitudes are measured.

amplitudes were measured. Note that the densest azimuthal coverage spans the range from $\mathrm{N} 10^{\circ} \mathrm{W}$ to $\mathrm{N} 135^{\circ} \mathrm{E}$. Nothing can be done to overcome the gap in coverage to the south if only standardized stations are used.

Using all available WWSSN and CSN records for each event, we have measured the first peak-to-first trough $(a b)$ amplitudes, equalized the instrument gains to unity at 1-sec period, and applied geometric spreading corrections (Langston and 
Helmberger, 1975) to equalize the data to $50^{\circ}$. In order to emphasize the common features in each amplitude set, we utilized the procedure described by Butler and Ruff (1980) to determine event size factors. This procedure minimizes the scatter at each station relative to a master event. When the event size factors are applied to the data, a relatively smooth average amplitude pattern for Pahute Mesa events is found as shown in Figure 5. The scatter in amplitude about the mean at each station is typically less than a factor of two, while the variation between stations is much greater. The stations are ordered with increasing azimuth from due North, but the azimuthal coverage is nonuniform. There are 1121 amplitude measurements in Figure 5. In comparing the relative $a b$ amplitudes, no correction for $p P$ interference has been made. For the Pahute Mesa events, the overburden velocities are so

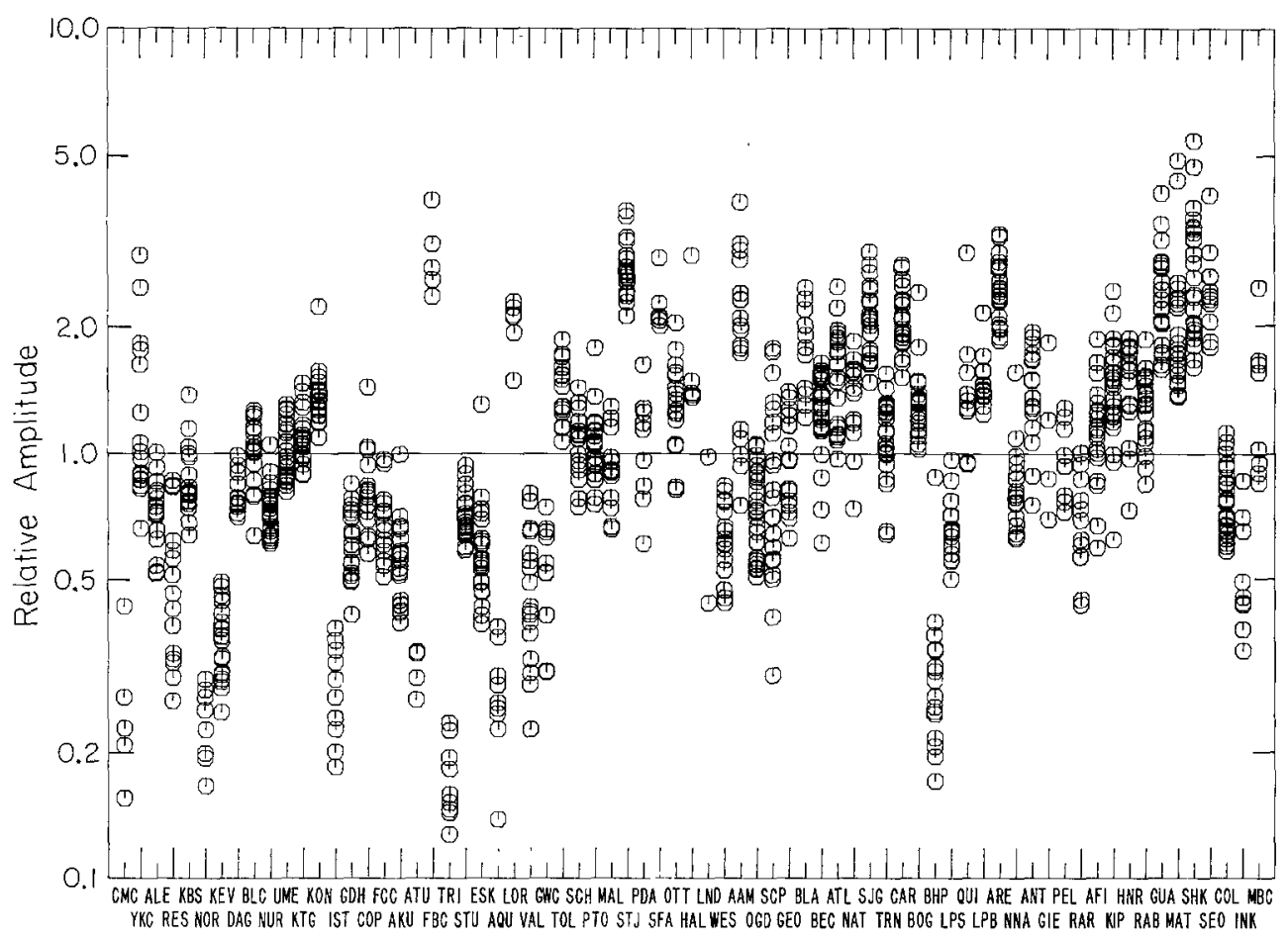

FIG. 5. The complete short-period $P$-wave $a b$ amplitude data set for 25 Pahute Mesa events plotted after applying corrections for event size. The stations are ordered in azimuth from the test site. There are 1121 amplitude measurements in this data set.

slow that for each event the $p P$ arrival is lagged by more than 0.6 sec (Springer, 1974). This means that, for these events, the $a b$ amplitude is usually a measure of the direct $P$ arrival alone. Figure 5 shows a general tendency for relatively low amplitudes to be recorded at European and western Canadian stations, as was noted by Helmberger and Hadley (1981). Stations TRI and BHP have anomalous waveforms with small precursory arrivals, for which the $a b$ amplitude measurement is not comparable with the other stations. Considering the range in yield of the events shown, the amplitude pattern is remarkably stable.

To better portray the basic Pahute Mesa teleseismic amplitude pattern, the average and standard error of the mean for each station in Figure 5 was computed. These are plotted as a function of azimuth from NTS in Figure 6. The relatively 
small scatter in amplitude at each station justifies characterizing the azimuthal pattern with the station averages. The striking feature of Figure 6 is that the amplitudes are uniformly low in the azimuth range $-10^{\circ}$ to $40^{\circ}$. There is at least a factor of three azimuthal variation in amplitude between azimuths of $20^{\circ}$ and $100^{\circ}$. A very similar pattern is observed for the first trough-to-second peak $(b c)$ amplitudes.

There are several possible explanations for the azimuthal pattern apparent in Figure 6 that have nothing to do with the source radiation. The pattern could result from systematic regional variations in upper mantle properties beneath the receivers, or from anomalous upper mantle structure beneath the source region. To appraise these possibilities, we measured the $a b$ amplitudes for the two Yucca Flat events BILBY and COMMODORE, the Climax Stock event PILEDRIVER, and for FAULTLESS, which was located $100 \mathrm{~km}$ north of NTS. The amplitudes for several of these events are compared with those for GREELEY in Figure 7. The

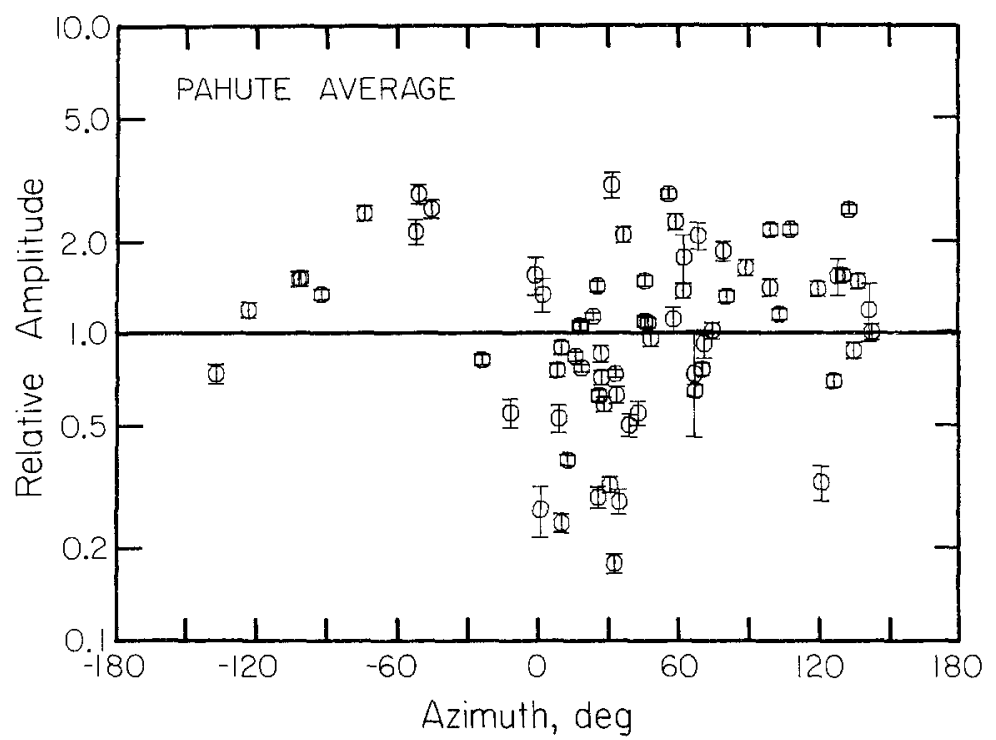

FIG. 6. Azimuthal plot of the mean and standard error of the mean amplitude of each station shown in Figure 5. The European stations define the low-amplitude cluster near $\mathrm{N} 25^{\circ} \mathrm{E}$.

azimuthal pattern apparent in the GREELEY data is not seen for any of the other events, which suggests that the pattern is not due to receiver effects. There are some similarities in the GREELEY and COMMODORE patterns, but significant differences are also apparent. It is interesting to note that FAULTLESS and PILEDRIVER have fairly similar patterns. This remarkable variation in the relative amplitudes of the first second of the $P$ waveforms indicates that near-source effects are very important. This variation also precludes reliable correction of the amplitudes for receiver effects. While it is conceivable that some, or all, of the Pahute Mesa amplitude pattern is due to receiver variations, and that the other events are all anomalous, we will explore the possibility that the pattern results from tectonic release below. The influence of near-source velocity structure is discussed later.

The Canadian stations operate higher frequency instruments than do the WWSSN stations, and thus one would expect that the amplitudes at these stations would be enhanced relative to the WWSSN observations, given the amplitude 
measurement procedure adopted. In Figure 7, the Canadian observations for GREELEY are indicated by the solid symbols. They do indeed appear to be baselineshifted relative to the WWSSN data. Because of the variation in instrument response between Canadian stations, and with time for each station, it is difficult to correct the amplitudes to WWSSN response. Since the Canadian data show the same azimuthal trend as the WWSSN stations, we will simply omit them, along with the multipathed stations TRI and BHP in the following.

The coherent azimuthal pattern in the Pahute Mesa amplitude data appears to have either a sinusoidal variation or a steplike variation with azimuth. We have chosen to fit $\sin (2 \phi)$ curves to the data, motivated by the sharp azimuthal variations
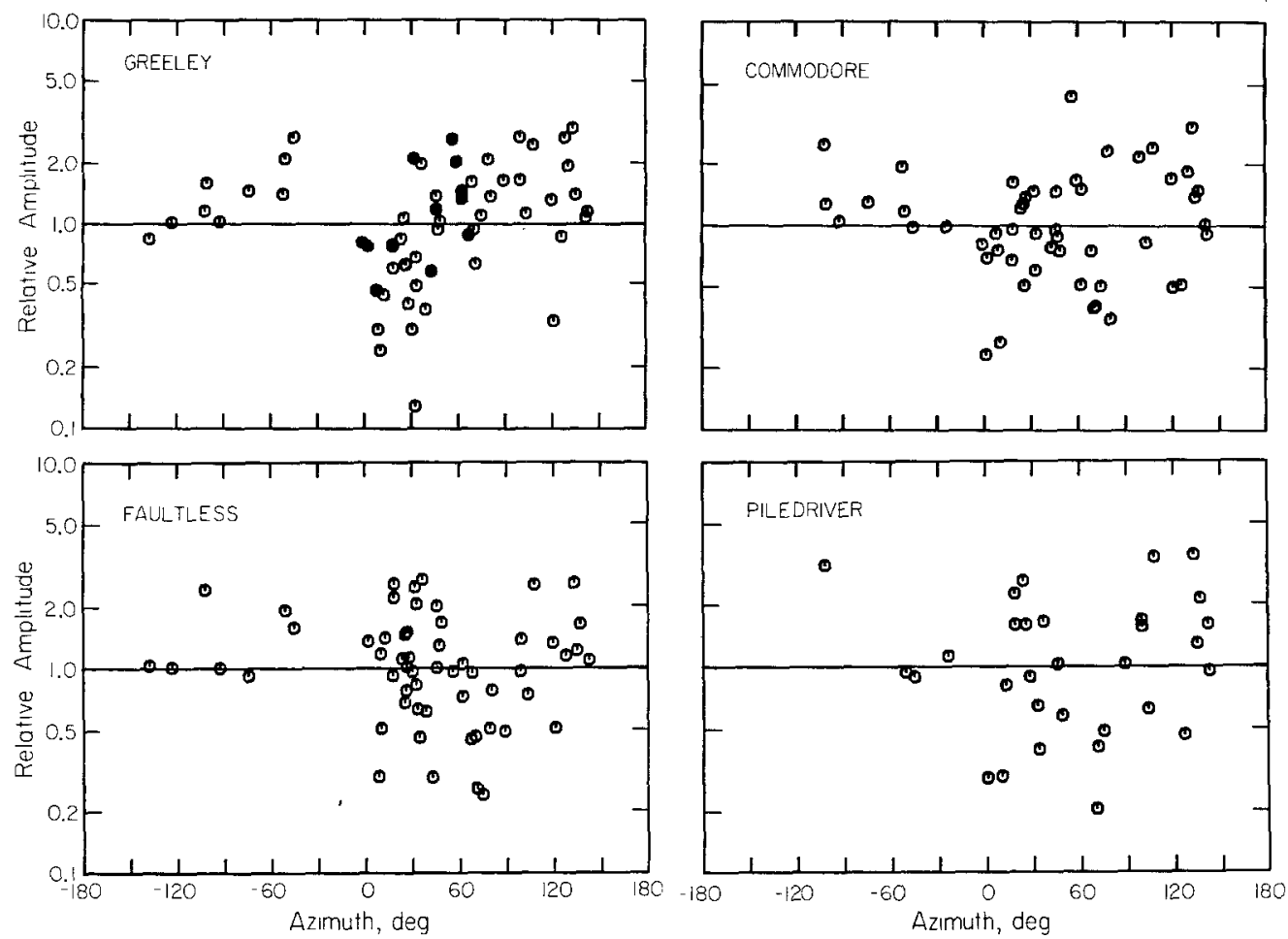

FIG. 7. Comparison of the azimuthal variation of short-period $a b$ amplitudes for GREELEY (Pahute Mesa) with those for FAULTLESS (100 km north of Pahute Mesa), COMMODORE (Yucca Flat), and PILEDRIVER (Climax Stock). The filled symbols for GREELEY are Canadian station data.

observed, and because of the obvious association with the azimuthal radiation pattern for vertical strike-slip faulting. The procedure adopted was the following. For each event, the mean $a b$ amplitude, $\bar{A}_{w w}$, of the WWSSN stations was determined, and the amplitudes were divided by $\overline{A_{w w}}$. A curve was fit to the zero mean ratios with the form

$$
\frac{A}{\bar{A}_{w w}}-1=a \sin \left[2\left(\phi-\phi_{0}\right)\right]
$$

The two parameters $a$ and $\phi_{0}$ were inverted for by least squares. Examples of the resulting fits are shown in Figure 8. Visually, it is clear that the sine curve follows 
the general trend of the data, which provides a useful means for summarizing the data. Note that the amplitude of the curve fit to the GREELEY data is larger than that for HANDLEY, as well as being slightly rotated. The sine curve amplitude, $a$, is a measure of the sinusoidal variation about the mean.

In order to provide a statistical test of the significance of the sine curve regressions
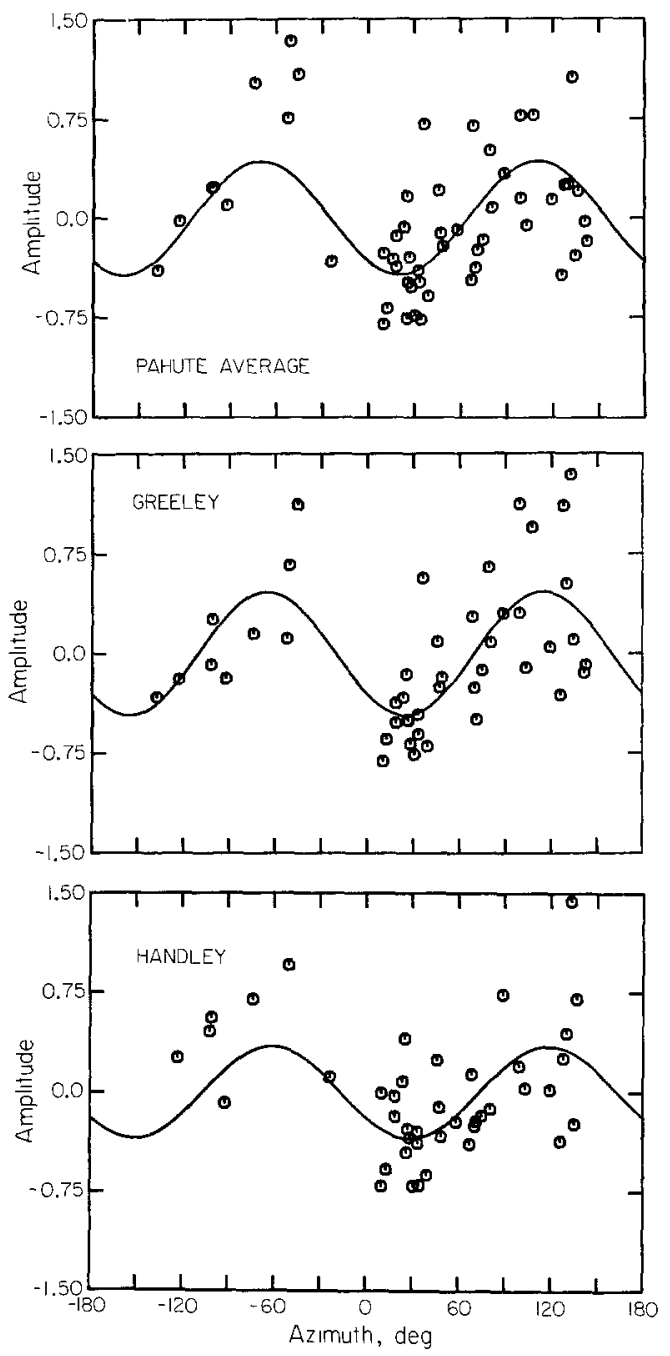

FIG. 8. Regression of $\sin (2 \phi)$ curves on the short-period amplitude data for the average station values for Pahute Mesa events (top), a high tectonic release event (GREELEY), and a lower tectonic release event (HANDLEY). The coefficients of the sine curves are given in Table 2. Only WWSSN stations are included to avoid any systematic instrument response bias between the CSN and WWSSN networks.

compared with simply finding the mean of the population, we have adopted the $f$ test (Draper and Smith, 1966). This is a test of the null hypothesis that the additional parameters $a$ and $\phi_{0}$ are equal to zero. The $f$ ratio is given by

$$
f=\frac{\left(R S S_{1}-R S S_{2}\right) /\left(D O F_{1}-D O F_{2}\right)}{\left(R S S_{2} / D O F_{2}\right)}
$$


where RSS refers to the residual sum of squares and DOF refers to the number of degrees of freedom. The subscripts 1 and 2 refer to models without and with the extra parameters, respectively. If $f$ is large, the null hypothesis is rejected.

The results of the sine curve inversions for each of the 25 Pahute Mesa events, the Pahute Mesa station averages, and the four additional NTS events are listed in Table 2. For reference, Table 2 includes yield estimates based on average $a b$

TABLE 2

ShORT-PERIOD AMPlitude ReSUlts FOR NTS EventS

\begin{tabular}{|c|c|c|c|c|c|c|c|c|c|c|}
\hline Event & Date & $\begin{array}{r}\text { Depth } \\
(\mathrm{km}) \\
\end{array}$ & $\begin{array}{c}A^{*} \\
(\mathrm{~m} \mu) \\
\end{array}$ & $N$ & $\begin{array}{c}Y \dagger \\
(\mathrm{kt})\end{array}$ & $\begin{array}{c}A_{w w \ddagger} \ddagger \\
(\mathrm{m} \mu)\end{array}$ & $N_{w w}$ & $a$ & $\begin{array}{c}\phi_{0} \\
(\mathrm{deg})\end{array}$ & $f$ \\
\hline PIPKIN & $10 / 08 / 69$ & 0.617 & 81 & 43 & 113 & 95 & 35 & 0.269 & 52.3 & $4.8 \S$ \\
\hline STINGER & $3 / 22 / 68$ & 0.668 & 88 & 42 & 126 & 96 & 31 & 0.471 & 80.7 & 6.9 \\
\hline SCOTCH & $5 / 23 / 67$ & 0.978 & 102 & 39 & 152 & 116 & 27 & 0.262 & 85.0 & $3.0 \pi$ \\
\hline PURSE & $5 / 07 / 69$ & 0.599 & 123 & 48 & 193 & 141 & 37 & 0.453 & 65.8 & 9.4 \\
\hline RICKEY & $6 / 15 / 68$ & 0.683 & 157 & 31 & 265 & 186 & 30 & 0.466 & 80.6 & $4.7 \S$ \\
\hline STILTON & $6 / 03 / 75$ & 0.731 & 162 & 49 & 276 & 157 & 39 & 0.359 & 68.5 & 7.1 \\
\hline ESTUARY & $3 / 09 / 76$ & 0.869 & 187 & 34 & 332 & 188 & 34 & 0.442 & 75.9 & 8.4 \\
\hline INLET & $11 / 20 / 75$ & 0.817 & 211 & 40 & 387 & 250 & 32 & 0.437 & 76.5 & $3.3 \pi$ \\
\hline SLED & $8 / 29 / 68$ & 0.729 & 218 & 41 & 404 & 246 & 34 & 0.479 & 83.7 & 6.7 \\
\hline CHESHIRE & $2 / 14 / 76$ & 1.167 & 236 & 38 & 448 & 262 & 37 & 0.387 & 57.9 & 6.1 \\
\hline POOL & $3 / 17 / 76$ & 0.879 & 244 & 39 & 467 & 256 & 37 & 0.458 & 74.6 & $5.2 \S$ \\
\hline TYBO & $5 / 14 / 75$ & 0.765 & 244 & 51 & 467 & 246 & 41 & 0.457 & 69.3 & 16.5 \\
\hline MAST & $6 / 19 / 75$ & 0.912 & 258 & 54 & 502 & 251 & 43 & 0.371 & 71.9 & 8.3 \\
\hline HALFBEAK & $6 / 30 / 66$ & 0.819 & 259 & 47 & 504 & 241 & 35 & 0.325 & 65.2 & 5.7 \\
\hline ALMENDRO & $6 / 06 / 73$ & 1.064 & 372 & 44 & 804 & 375 & 34 & 0.429 & 79.6 & 9.1 \\
\hline CAMEMBERT & $6 / 26 / 75$ & 1.311 & 423 & 45 & 949 & 418 & 38 & 0.450 & 65.2 & 14.8 \\
\hline GREELEY & $12 / 20 / 66$ & 1.215 & 426 & 60 & 958 & 473 & 45 & 0.465 & 69.7 & 17.7 \\
\hline MUENSTER & $1 / 03 / 76$ & 1.451 & 487 & 40 & 1138 & 504 & 36 & 0.448 & 60.1 & 9.0 \\
\hline JORUM & $9 / 16 / 69$ & 1.158 & 489 & 57 & 1144 & 467 & 44 & 0.462 & 67.5 & 15.9 \\
\hline KASSERI & $10 / 28 / 75$ & 1.265 & 489 & 43 & 1144 & 499 & 38 & 0.527 & 64.0 & 13.2 \\
\hline BOXCAR & $4 / 26 / 68$ & 1.158 & 495 & 48 & 1162 & 511 & 37 & 0.575 & 71.4 & 19.4 \\
\hline BENHAM & $12 / 19 / 68$ & 1.402 & 505 & 50 & 1192 & 499 & 37 & 0.501 & 58.4 & 20.8 \\
\hline FONTINA & $2 / 12 / 76$ & 1.219 & 526 & 40 & 1257 & 561 & 36 & 0.509 & 65.6 & 11.4 \\
\hline COLBY & $3 / 14 / 76$ & 1.273 & 601 & 45 & 1492 & 637 & 37 & 0.472 & 65.9 & 10.5 \\
\hline HANDLEY & $3 / 26 / 70$ & 1.206 & 697 & 53 & 1806 & 609 & 42 & 0.346 & 73.3 & 9.7 \\
\hline Pahute Average & & & & & & & 53 & 0.431 & 65.3 & 16.7 \\
\hline FAULTLESS & $1 / 19 / 68$ & 0.975 & & & $1200 \|$ & 487 & 45 & 0.281 & 116.8 & $2.3 \pi$ \\
\hline COMMODORE & $5 / 20 / 67$ & 0.746 & & & $250 \|$ & 176 & 37 & 0.273 & 77.7 & $3.0 \%$ \\
\hline BILBY & $9 / 13 / 63$ & 0.714 & & & $235 \|$ & 142 & 24 & 0.147 & 83.3 & 0.8 \\
\hline PILEDRIVER & $6 / 02 / 66$ & 0.500 & & & $56 \|$ & 117 & 30 & 0.187 & 91.2 & $0.6 \pi$ \\
\hline
\end{tabular}

* Average $a b$ amplitude of N WWSSN and CSN observations with station corrections.

$\dagger$ Yield estimated from $\log A=0.3151+0.7763 \log Y$.

$\$$ Average $a b$ amplitude of $N_{w w}$ WWSSN observations.

$\S$ Fails $f$ test at 99 th percentile.

$\uparrow$ Fails $f$ test at 95 th percentile.

\| Announced yield.

amplitudes from the WWSSN and CSN observations. The average station anomalies in Figure 6 were used as station corrections in computing these averages. The yields were then estimated by regressing $\log A$ on $\log$ yield using the Pahute events with announced yields (SCOTCH, BENHAM, BOXCAR, and GREELEY). The resulting yields are generally similar to those estimated by Dahlman and Israelson (1977) and are intended only to indicate the relative explosion sizes inferred from 
our data. Events failing to reject the null hypothesis at the 95 and 99 per cent confidence levels are indicated by x's in Table 2. For the Pahute Mesa events, only 5 of the 25 events fail the $f$ test at the 99 per cent confidence level and only two at the 95 per cent confidence level. However, all four non-Pahute Mesa events fail at the 95 per cent confidence level.

Since the $f$ ratio is basically a measure of the variance reduction with the $\sin (2 \phi)$ fit, the larger the $f$ ratio the more closely the data follows a $\sin (2 \phi)$ pattern. Given the large intrinsic scatter in the data, the $f$ ratio is probably a more reliable parameter than the amplitude of the sinusoid, $a$, to use in comparing the events. If the larger events are ordered by size of the $f$ ratio, the first five events would be BENHAM, BOXCAR, GREELEY, JORUM, and CAMEMBERT. Referring to Figure 3 and Table 2, it is clear that those events with evidence for strong tectonic release show the clearest $\sin (2 \phi)$ azimuthal behavior. MUENSTER deviates from this trend. This point is further illustrated in Figure 9. Each Pahute Mesa event is

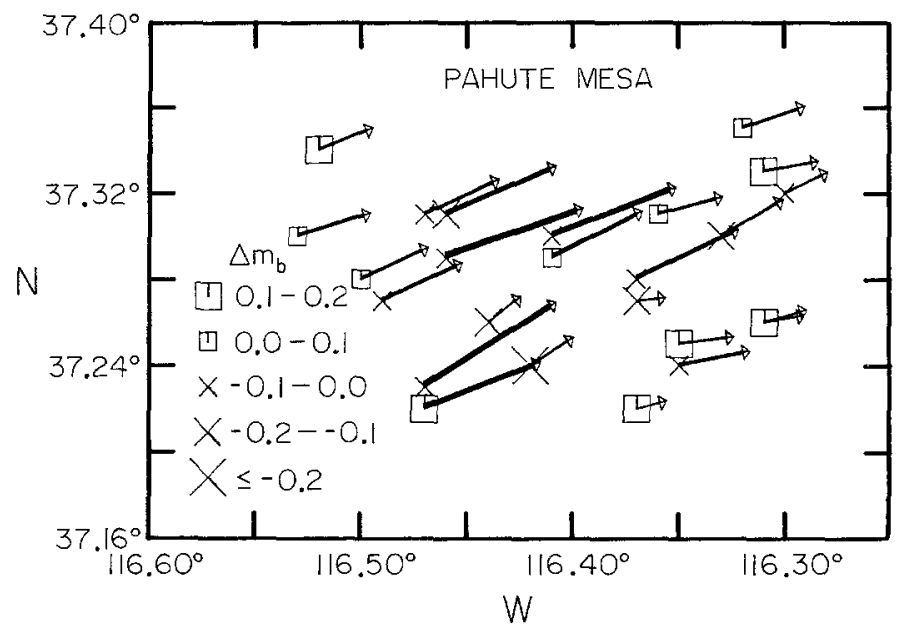

FiG. 9. For each of the events in Figure 4, an arrow is shown for which the width and length are proportional to the $f$ ratio, and the azimuth is given by $\phi_{0}$ for that event. The $f$ ratio is large for those events for which a $\sin (2 \phi)$ curve significantly reduces the variance. The symbols also indicate the $\Delta m_{b}$ for each event, with positive $\Delta m_{b}$ indicating larger than expected amplitudes.

plotted with an arrow for which the length and width are proportional to the $f$ ratio, and the direction is given by $\phi_{0}$, which corresponds to the zero crossing beneath negative and positive quadrants in equation (1). The association between large tectonic release moment and high $f$ ratios is apparent in Figures 3 and 9. Figure 9 also shows the $\Delta m_{b}$ for each event determined by Alewine et al. (unpublished data) as reported by Minster et al. (1981). Positive $\Delta m_{b}$ corresponds to enhanced amplitudes. There is a weak association between the $\Delta m_{b}$ values and the $f$ ratios; larger $f$ ratios tend to have negative $\Delta m_{b}$. There is also a tendency for positive $\Delta m_{b}$ to correlate with slight clockwise rotations of $\phi_{0}$ except in the western part of the Mesa. These correlations suggest the possibility that whatever is causing the azimuthal amplitude pattern for Pahute Mesa events and the slight internal variations is influencing average $m_{b}$ estimates.

We will now turn our attention to the question of whether there are any systematic waveform characteristics associated with the azimuthal amplitude variations. Figure 10 shows the azimuthal variation in the short-period $P$ waveforms for GREELEY 
and COLBY. Table 1 and Figures 2 and 3 indicate that GREELEY has significantly more long-period tectonic release than COLBY. In the center of Figure 10, the $P$ wave radiation pattern for a strike-slip orientation consistent with the long-period tectonic release results is shown. At northeastern azimuths, the tectonic release $P$ wave would have opposite polarity to the explosion arrival. Any signature of the differential tectonic release on the first few seconds of the $P$ waveforms must be rather subtle. In order to account for the azimuthal variation of the $a b$ amplitudes, any tectonic release component must arrive with the direct $P$ wave. Therefore, one might expect the relative $a b / b c$ amplitude ratios to be sensitive to the differential amount of tectonic release between the events. Stations near the double-couple nodes should show the least effect. There is a weak tendency for the waveforms to differ most at azimuths in the loop directions of the double couple. For instance, the $a b$ amplitude is small relative to the rest of the waveform for GREELEY at

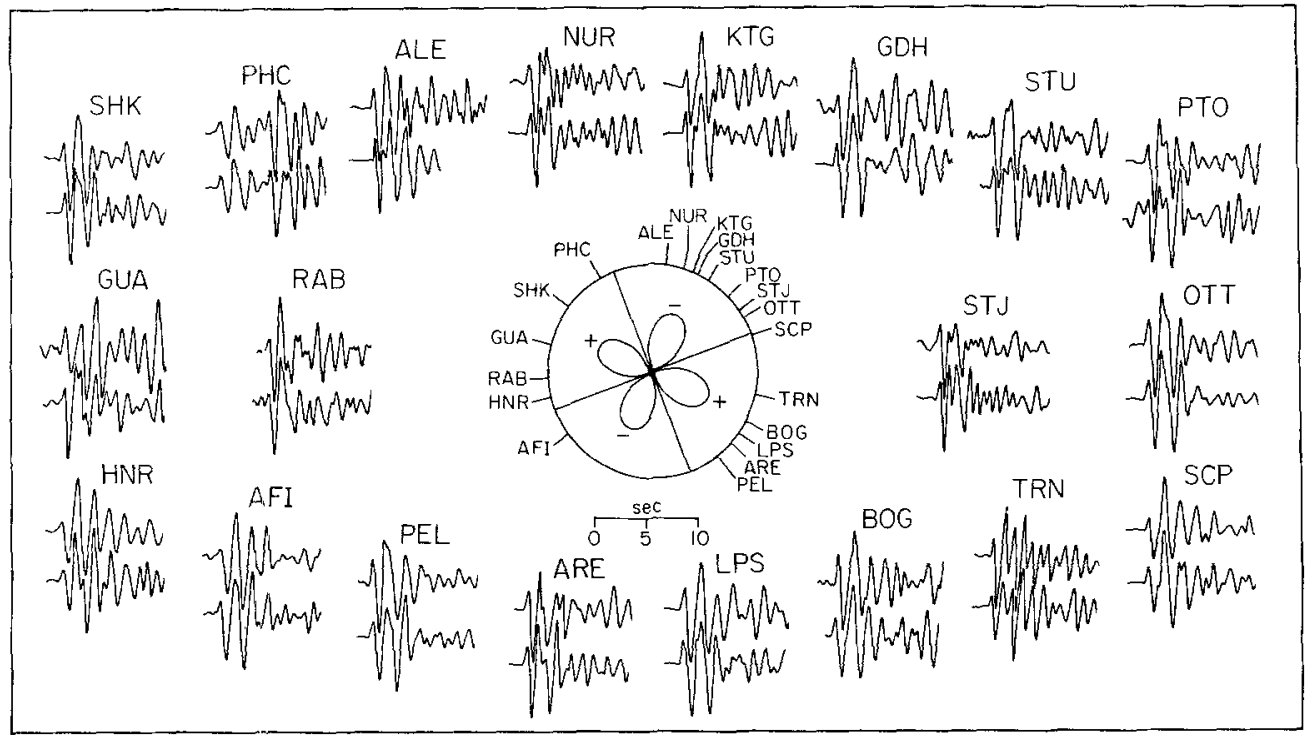

FIG. 10. Comparison of the short-period $P$ waveforms for GREELEY (top trace) and COLBY at different azimuths from the source region. The azimuths are indicated on the circle. Within the circle, the $P$-wave radiation pattern predicted for the tectonic release orientation constrained by long-period observations of GREELEY is shown. The negative lobes would be opposite in polarity to the explosion arrival.

KTG and GDH, and large at BOG and TRN. However, there are several stations that show opposite trends, and many show no significant differences at all. Allowing for the substantial variations between stations in the path and receiver complexities, it is clear that the mechanism producing the azimuthal variations in amplitude for Pahute Mesa events does not necessarily produce obvious waveform differences from event to event.

More comparisons of short-period $P$ waveforms from NTS events are presented in Figure 11. Observations at stations UME $\left(\phi=19^{\circ}\right)$ and OGD $\left(\phi=70^{\circ}\right)$ are shown for 13 of the larger Pahute Mesa events, and FAULTLESS, COMMODORE, and PILEDRIVER. For a right-lateral, strike-slip double-couple trending near $\mathrm{N} 20^{\circ} \mathrm{W}$, which is the orientation indicated by long periods, UME would lie in the negative loop of the $P$-wave amplitude radiation pattern, while OGD would lie along the $P$ wave node. Thus, if all of the events had similar, but varying degrees of strike-slip 
tectonic release with sufficient high-frequency energy to affect the short-period signals, the waveforms should vary more at UME than at OGD. Of course, some variations are expected due to the slight differences in source function, burial depth, and very near-source structure. It is interesting to first note that for FAULTLESS, the two stations recorded nearly identical waveforms, and while Pahute Mesa observations look similar to those recorded for FAULTLESS at OGD, UME is quite different. PILEDRIVER and COMMODORE differ in appearance at both stations from all of the other events. Among the Pahute Mesa events, HALFBEAK

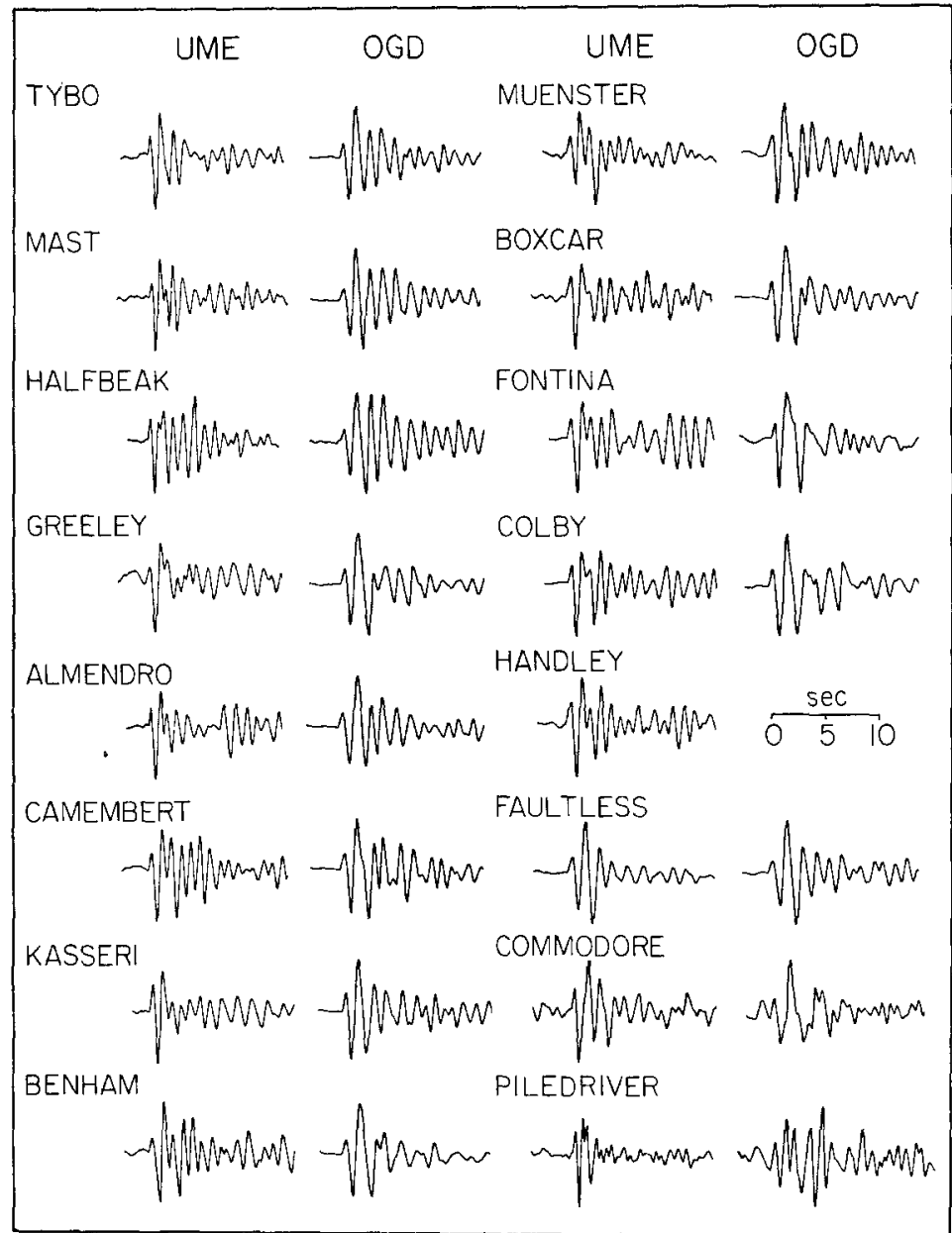

FIG. 11. Short-period $P$-wave observations for various NTS events at WWSSN stations UME and OGD. The peak amplitudes are equalized to unity. UME is at an azimuth of $19^{\circ}$ and OGD is at $70^{\circ}$.

and CAMEMBERT have more complicated codas in the first 5 sec after the $P$ arrival, as does CHESHIRE (not shown). HALFBEAK and CHESHIRE were observed to be more complicated in the long-period records at SHA in Figure 3. UME does appear to show more variation than OGD, although the higher frequency content of the signals probably influences this. For several events, such as HANDLEY, COLBY, FONTINA, BENHAM, ALMENDRO, and MAST, the waveforms at both stations are very similar from event to event. BENHAM is known to have a larger long-period component of tectonic release than the others, but is not 
distinctive in appearance. However, MUENSTER and GREELEY, which also have large $F$ factors, do have different waveforms at UME. Figure 11 is intended only to indicate the degree to which the waveforms do or do not vary from event to event. It is clearly necessary to simultaneously consider the variations at all 71 stations for which short-period amplitudes and waveforms were collected. Such a quantitative analysis is being performed using a relative waveform comparison technique (Lay, 1984 in preparation).

This section has demonstrated that all Pahute Mesa events show a short-period $P$-wave amplitude azimuthal pattern. Diminished amplitudes are recorded in the $\mathrm{NNE}$ azimuth from the test site, with about a factor of three variation in the amplitude of the first cycle ( $\sim 0.6 \mathrm{sec}$ into the waveform) of the $P$ waves between azimuths of $20^{\circ}$ and $100^{\circ}$. The azimuthal coverage is not complete, but the data are compatible with a $\sin (2 \phi)$ azimuthal amplitude variation. The $\sin (2 \phi)$ component is more apparent for events known to have large $F$ factors. The waveform variations between events with low and high $F$ factors appear to be fairly subtle in all cases.

\section{Simulations of Short-Period Tectonic Release Effects}

It is clear that any form of tectonic release which is going to affect the shortperiod $a b$ amplitude must be generated at the same time as the explosion, or must be generated by the $P$ wave from the explosion. Bache (1976) has shown that application of the stress relaxation model of Archambeau (1972) for reasonable selection of the many parameters in that model, predicts negligible effect on teleseismic short-period signals, if the equivalent double couple is vertical strike slip. The long-period studies of tectonic release for Pahute Mesa events discussed earlier suggest that for at least several of the events the tectonic release orientation is strike slip, and furthermore, has a substantial high-frequency component $(<1$ sec) which strongly effects the long-period $P$ waveforms. This indicates that in addition to any radiation from the relaxation around the explosion cavity, there must be an additional source of high-frequency teleseismic $P$ energy. Because any effect on the short-period $a b$ amplitude implies an effect on $m_{b}$, which is the primary measurement used to estimate yield, it is important to determine whether the tectonic release observed in long-period records could be responsible for the shortperiod observations.

Several simple calculations in which the teleseismic short-period $P$ wave from an explosion is added to the teleseismic $P$ wave produced by a shear dislocation point source or finite source will now be described. Hartzell et al. (1983) have determined a crustal $P$ and $S$ velocity structure for Pahute Mesa events by modeling near-field signals from several explosions. They also developed source representations using the modified Haskell source model of Helmberger and Hadley (1981) for several events as well as a global average $t^{*}=0.75 \mathrm{sec}$ for the NTS test site and the WWSSN network. Using their results, we have applied scaling relations to estimate the source parameters for GREELEY $\left(K=8, B=1, \Psi_{\infty}=7.6 \times 10^{10} \mathrm{~cm}^{3}\right)$. Adopting a $p P-P$ lag time of $0.85 \mathrm{sec}$ and an elastic $p P$ reflection coefficient $\left(R_{p p}=0.96\right)$, generalized ray theory was used to produce a short-period teleseismic $P$-wave synthetic for the explosion at $50^{\circ}$. The $a b$ amplitude of the synthetic $(440 \mathrm{~m} \mu)$ is equal to the average, distance-corrected amplitude for WWSSN observations of GREELEY. As long as the latter result is satisfied, the actual parameters in the synthetic are not very important, but we feel that our calculation is a realistic one, for at least the first second of the waveform. The effects of spall, nonelastic $p P$ 
reflection and other complexities are not important for the $a b$ amplitude. For the double-couple contribution, we adopted a source depth of $3 \mathrm{~km}$ (point source models) or from 2 to $4 \mathrm{~km}$ (finite source models), and again used the Pahute Mesa velocity structure in the calculations. The earth model, receiver structure, and $t^{*}$ are the same as in the explosion calculation.

The important parameters in the double-couple calculation are the moment, the time function, and the timing relative to the explosion. For the double-couple moment, we use $4 \times 10^{24}$ dyne-cm, which is appropriate for GREELEY (Table 1) at long periods. Since the long-period $P$ waves indicate a time function with a duration of $0.6 \mathrm{sec}$ or so, we use a 0.55 -sec duration trapezoid $(0.2,0.3$, and 0.05$)$ for the time function. The slight asymmetry of the trapezoid is such that it is equivalent to the downgoing energy for the finite source discussed below. Upgoing rays have the same source function for this point source model. The $P$ arrival is aligned with that from the explosion, a necessary condition if the $a b$ amplitude is to be affected. This implies that the downgoing $P$ wave drives the dislocation. Such a model is discussed by Andrews (1973). We constrain the orientation of the mechanisms by requiring that one fault plane trend $\mathrm{N} 70^{\circ} \mathrm{E}$. It is important to emphasize that, with the exception of the relative start time of the two sources, all of the parameters selected are required by the long-period $P$-wave observations (Wallace et al., 1983), and the start times are compatible with them.

Figure 12 shows the azimuthal $a b$ amplitude variations for the observations of GREELEY (top) and three point source plus explosion models (middle). The three cases are for pure vertical strike slip $(\theta)$, strike slip with the northward trending plane dipping $75^{\circ}$ to the west $(+)$, and strike slip with a rake of $195^{\circ}$ on the northward trending fault $(x)$. The amplitude scales are equivalent for the data and synthetics. A remarkable result is that for the vertical strike-slip point source, a factor of $2.5 a b$ amplitude variation is predicted with the expected $\sin (2 \phi)$ azimuthal variation. Changing the dip or rake slightly rapidly alters the $\sin (2 \phi)$ pattern, but allows an even greater azimuthal variation across the azimuth $N 70^{\circ} \mathrm{E}$. Since 90 per cent of the data lie in the eastern azimuths, the deterioration of the $\sin (2 \phi)$ pattern may not be significant. Recalling that these calculations are essentially predictions based on the long-period results, it would appear that it is possible to explain the magnitude and orientation of the teleseismic short-period amplitude variations by tectonic release of a nature consistent with and required by long-period signals.

If the $P$ wave drives the dislocation, the implied rupture velocity is the $P$-wave velocity of the medium. A finite source calculation was made for a downward propagating, vertical strike-slip line-source $2 \mathrm{~km}$ long extending from 2 to $4 \mathrm{~km}$ deep. The azimuthal variation of $a b$ amplitudes for this case are compared with those for the point source with equivalent time function in Figure 12 (bottom). The finiteness effects slightly enhance the $a b$ amplitude variations as one would expect for downgoing rupture, with a slight asymmetry introduced by differences in the frequency content of the explosion and double-couple signals.

Given the lack of obvious waveform variations for events with varying degree of tectonic release demonstrated in the last section, it is important to consider whether the amplitude effects predicted in Figure 12 are accompanied by waveform variations that would rule out such models. Figure 13 presents the synthetic waveforms for the explosion alone, and the vertical strike-slip dislocation models. The first column indicates the explosion signal and the tectonic release signals in the loop directions for the point source and finite source. Note that the $a b$ amplitudes are comparable. 
The next two columns show the explosion plus double-couple waveforms in the positive and negative loop directions. The finite source synthetics are less complicated than the point source synthetics because the downward directivity produces destructive interference for the $s P$ arrival. Thus, the finite source produces less waveform variation with azimuth. Even for the point source model, although, the

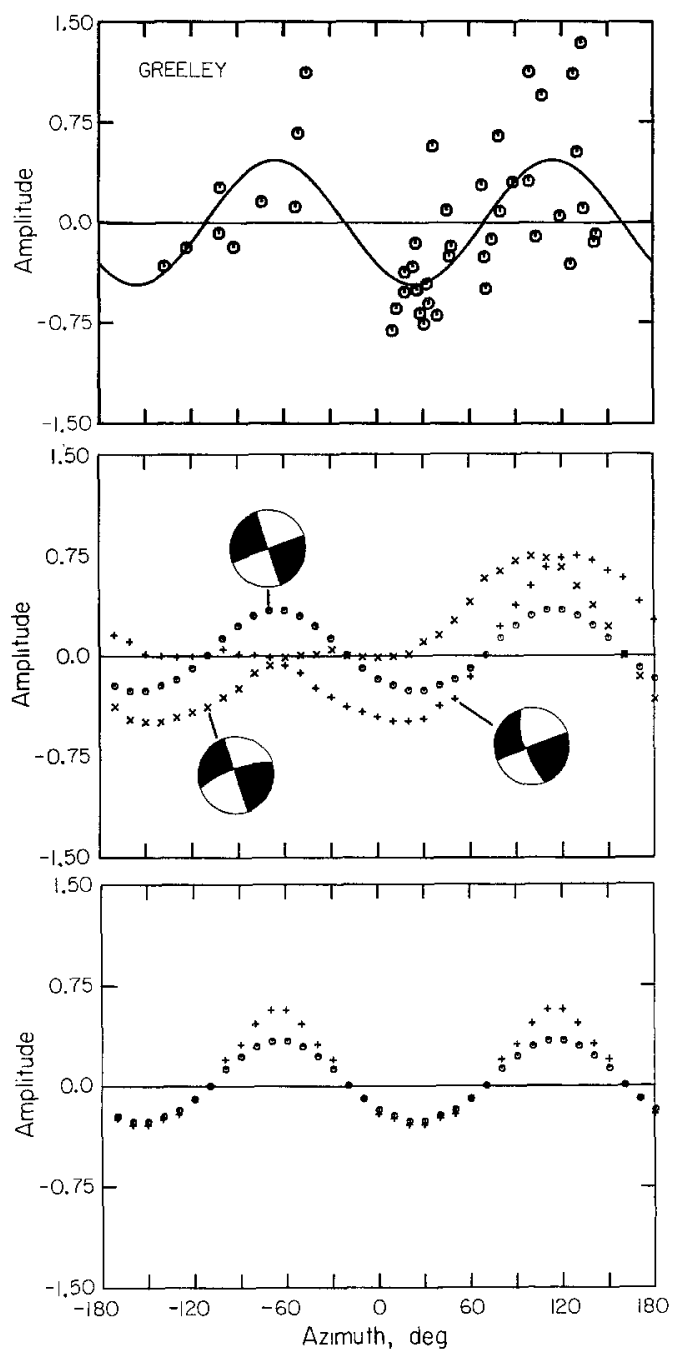

FIG. 12. (Top) Short-period $a b$ amplitudes for GREELEY along with the best fit $\sin (2 \phi)$ curve. (Middle) Synthetic calculations of short-period $a b$ amplitudes for GREELEY with explosion plus doublecouple point sources. Note the agreement in amplitude and azimuthal variation of the vertical strike slip source $(\theta)$, with the observations. (Bottom) Comparison of short-period $a b$ amplitude variations for a vertical strike-slip point source model, $(\theta)$, and a downward rupturing vertical strike-slip finite source model with equivalent moment and time function $(+)$.

azimuthal variation is quite subtle, and the first order effect is the amplitude variation. Referring to Figure 10, it is unlikely that such variations could be resolved given the additional path, receiver, and near-source contributions to the coda. Note that the finite source produces nearly uniform suppression of the explosion waveform, thus the $b c$ amplitudes show the same pattern as the $a b$ amplitudes, which is what is actually observed. 


\section{Discussion}

The teleseismic short-period synthetics presented in the previous section showed that the observed azimuthal amplitude variation is consistent in amplitude and orientation with that expected based on previous long-period body wave and surface wave analysis if the tectonic release is driven by the $P$ wave from the explosion. However, several important questions must be addressed. The first is: if tectonic release is responsible for the $a b$ variations, why does it occur for every event? While events with larger tectonic release moments were shown to have more robust $\sin (2 \phi)$ amplitude patterns, the fact remains that all of the events show the general pattern peculiar to Pahute Mesa. While some events appear to have triggered slip on

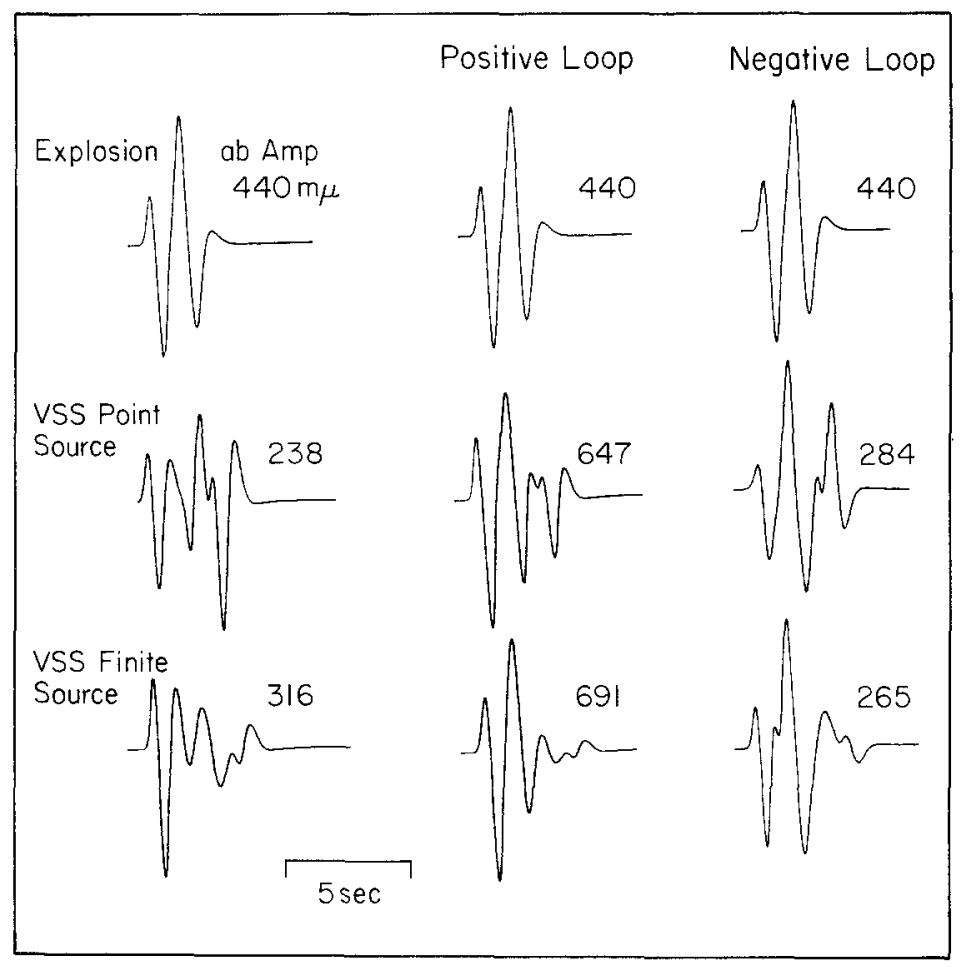

FIG. 13. Short-period synthetic waveforms for the GREELEY simulation. The top row shows the explosion synthetic alone. The middle row shows the vertical strike-slip point source synthetic, and the sum of the bomb + point source in the positive loop and negative loop directions of the double-couple radiation pattern. The bottom row is similar to the middle row, only it shows the downward rupturing finite source synthetic results.

adjacent faults (e.g., BENHAM; Aki and Tsai, 1972), this type of phenomenon seems unlikely to have occurred for all events. Similarly, while, in the presence of regional prestress, stress release accompanying the explosions must occur for each test, Bache (1976) has shown that the short-period teleseismic effects are probably minor for reasonable selection of the parameters in Archambeau's (1972) model.

We feel that in order to account for the teleseismic short-period variations with tectonic release, a slight modification of the stress relaxation model could be made. Given a predominantly strike-slip regional stress regime, it seems plausible that the radially cracked region surrounding the explosion could develop preferred orientations with depth. That is to say that when the explosion occurs, the pressure wave from the explosion could induce slip on a distributed network of joints and minor 
faults underlying the Mesa at depths of 2 to $4 \mathrm{~km}$ that would respond to the regional stress field. This would result in a preferential downward extension of the radially cracked region, along the lines schematically indicated in Figure 14. The downgoing ruptures would interfere with the direct $P$ wave in the same manner as in the synthetics. Some tectonic release would thus accompany every event.

The stress drop implied by the finite source synthetic in Figure 13 is on the order of 600 bars, but this number would be significantly reduced if a network of faults were activated, thereby increasing the source area. Since the rupture occurs at depths around $3 \mathrm{~km}$, the efficiency of the radiated energy is enhanced over shallower sources, which is a major reason why generating the observed amplitude effects from the shatterzone alone is very difficult. Wallace et al. (1983) suggested that events within $2 \mathrm{~km}$ of a previous large tectonic release event tend to have lower

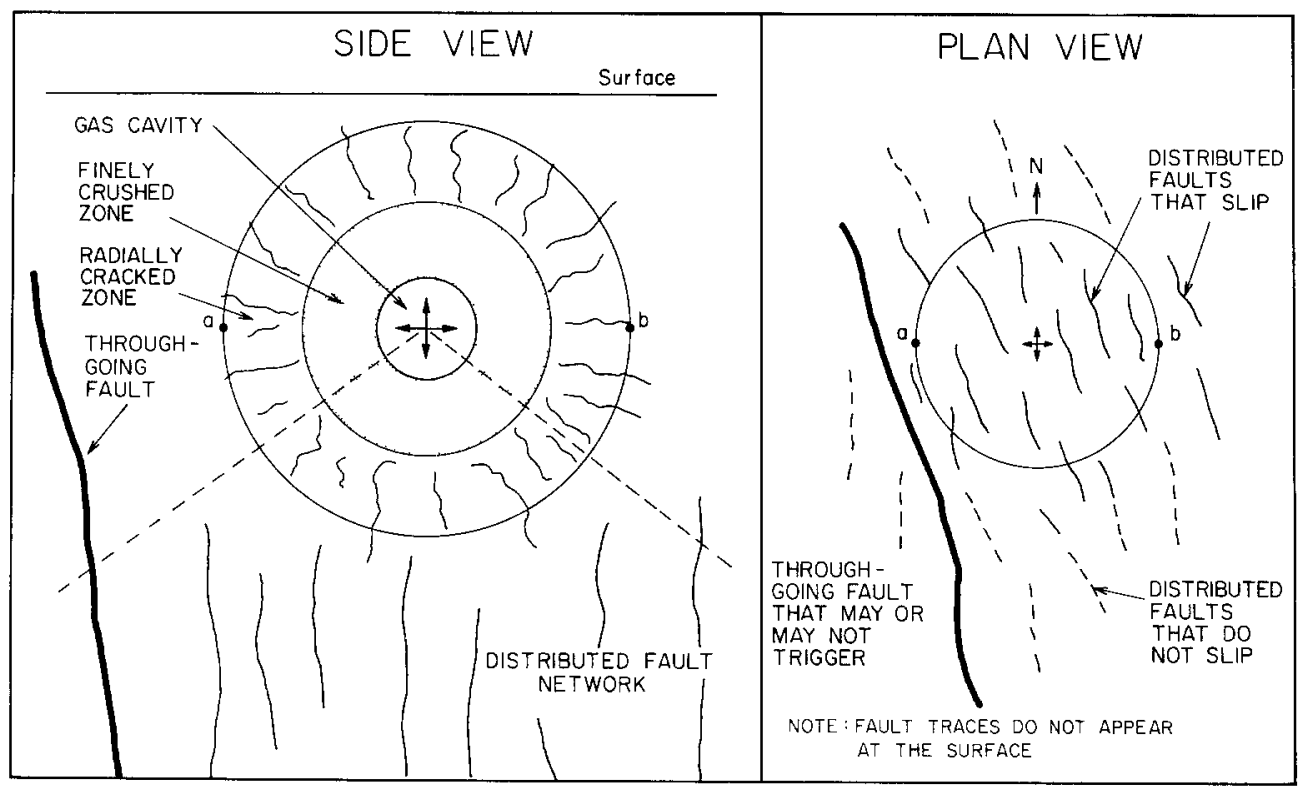

FIG. 14. A possible model of the tectonic release mechanism which could account for the amplitude pattern observed for all Pahute Mesa events. The standard model (Archambeau, 1972) of the environment surrounding the explosion cavity is shown. If a distributed network of faults underlies the Mesa at depths of 2 to $4 \mathrm{~km}$, the radially cracked zone could be extended preferentially downward by activation of the fault network. The overall radiation would reflect the regional stress field.

tectonic release, whereas a $4 \mathrm{~km}$ or greater separation does not appear to influence the degree of tectonic release. Thus, if the distributed network of faults is activated over a region not much greater than the radially cracked zone, each event could have a similar high-frequency component of tectonic release. The fact that tests at other sites produce very different $a b$ amplitude patterns indicates that this special geometry may be unique to Pahute Mesa, but similar mechanisms may operate elsewhere.

The approach we have adopted in this paper is a cautious one, in that our intent has been to compare actual observed short-period amplitude and waveform characteristics with predictions of possible variations based on models constrained by well-documented, long-period studies. Such an approach is deemed necessary given our limited understanding of the short-period wave propagation processes in the earth and of the high-frequency details of underground explosions. The fundamental 
result of this paper is that it is quite possible that tectonic release can affect teleseismic short period amplitudes to a degree comparable to the variations produced by receiver, scattering, and focussing phenomena. This conclusion remains valid whether or not the Pahute Mesa amplitude pattern actually results from tectonic release or other effects. The most likely alternate interpretation of the teleseismic amplitude variations is that they are produced by upper mantle focussing/defocussing effects. This requires, of course, the remarkable coincidence that such mechanisms happen to produce an azimuthal pattern which is so consistent with the long-period tectonic release radiation pattern. Since all Pahute Mesa events show similar patterns, shallow crustal structure such as proposed to affect $m_{b}$ values for Yucca Flat events (Hart et al., 1979; Ferguson, 1981) are not a likely explanation. Systematic receiver effects do not appear to be the entire explanation either, based on comparison with nearby sources. The upper mantle structure beneath Pahute Mesa is known to have lateral variations, with a relatively highvelocity body apparent to depths exceeding $100 \mathrm{~km}$ below, and possibly trending northward from the caldera (Minster et al., 1981; Taylor, 1983). It will be important to determine whether such a structure can account for the teleseismic amplitude pattern, and the lack of it for Yucca Flat events, before definitive statements about tectonic release affects on $m_{b}$ can be made. However, the simple calculations presented above indicate that quantifying the tectonic release effects on long-period $P$ and $S$ waves is a crucial step in evaluating short-period signals.

\section{CONCLUSIONS}

Pahute Mesa underground nuclear tests produce teleseismic short-period $P$ waves with a systematic azimuthal amplitude variation. It is possible to account for this azimuthal variation by interference between the explosion and tectonic release $P$ waves, where the parameters of the tectonic release are constrained to be those indicated by long-period studies. Nearly vertical, high stress drop, strike-slip faulting is required by long-period $P$ waves from Pahute Mesa events. This predicts a factor of 2.0 to 3.0 -amplitude variation with a $\sin (2 \phi)$ azimuthal distribution for shortperiod teleseismic $P$ waves, if the tectonic release is driven by the explosion. The orientation and amplitude of the azimuthal variations in the observations are consistent with this prediction. If tectonic release is in fact responsible for the short-period variations, a model in which a distributed network of joints and faults, underlying Pahute Mesa at depths of 2 to $4 \mathrm{~km}$, is driven by the underground explosions, could account for the observations. The extent to which other factors influence the amplitude variations has not been determined, but tectonic release, even with strike-slip orientation, appears to be a plausible explanation for the data.

\section{ACKNOWLEDGMENTS}

We thank Larry Burdick for his comments. We appreciate the assistance of Gladys Engen in generating the synthetics in Figure 3, and Cindy Arvesen who digitized the waveforms and typed the manuscript. This research was supported by the Advanced Research Projects Agency of the Department of Defense and was monitored by the Air Force Office of Scientific Research under Contract F49620-83-C-0025.

\section{REFERENCES}

Aki, K. (1964). A note on surface waves from the HARDHAT nuclear explosion, J. Geophys. Res. 69, 1131-1134.

Aki, K. and Y.-B. Tsai (1972). Mechanism of Love-wave excitation by explosive sources, J. Geophys. Res. 77, 1452-1475. 
Aki, K., P. Reasenberg, T. DeFazio, and Y.-B. Tsai (1969). Near-field and far field seismic evidence for triggering of an earthquake by the BENHAM explosion, Bull. Seism. Soc. Am. 59, 2197-2207.

Aki, K., M. Bouchon, and P. Reasenberg (1974). Seismic source function for an underground nuclear explosion, Bull. Seism. Soc. Am. 64, 131-148.

Andrews, D. J. (1973). A numerical study of tectonic stress release by underground explosions, Bull. Seism. Soc. Am. 63, 1375-1391.

Archambeau, C. B. (1972). The theory of stress wave radiation from explosions in prestressed media, Geophys. J. 29, 329-366.

Archambeau, C. and C. Sammis (1970). Seismic radiation from explosions in prestressed media and the measurement of tectonic stress in the earth, Rev. Geophys. Space Phys. 8, 473-499.

Bache, T. C. (1976). The effect of tectonic stress release on explosion $P$-wave signatures, Bull. Seism. Soc. Am. 66, 1441-1457.

Brune, J. N. and P. W. Pomeroy (1963). Surface wave radiation patterns for underground nuclear explosions and small-magnitude earthquakes, J. Geophys. Res. 68, 5005-5028.

Burdick, L. and D. V. Helmberger (1978). The upper mantle $P$ velocity structure of the western United States, J. Geophys. Res. 83, 1699-1712.

Butler, R. and L. Ruff (1980). Teleseismic short-period amplitudes: source and receiver variations, Bull. Seism. Soc. Am. 70, 831-850.

Dahlman, O. and H. Israelson (1977). Monitoring Underground Nuclear Explosions, Elsevier, New York, $440 \mathrm{pp}$.

Draper, N. R. and H. Smith (1966). Applied Regression Analysis, John Wiley \& Sons, Inc., New York.

Ferguson, J. (1981). Geophysical Investigations of Yucca Flat, Nevada, Ph.D. Thesis, Southern Methodist University, Dallas, Texas.

Hart, R. S., D. M. Hadley, G. R. Mellman, and R. Butler (1979). Seismic amplitude and waveform research, Final Technical Report SGI-R-79-012, Sierra Geophysics, Seattle, Washington.

Hartzell, S., L. Burdick, and T. Lay (1983). Analysis of effective source functions and near field phenomena, Final Technical Report WWCP-R-83-01, Woodward-Clyde Consultants, Pasadena, California.

Helmberger, D. V. and D. M. Hadley (1981). Seismic source functions and attenuation from local and teleseismic observations of the NTS events JORUM and HANDLEY, Bull. Seism. Soc. Am. 71, $51-67$.

Hirasawa, T. (1971). Radiation patterns of $S$ waves from underground nuclear explosions, J. Geophys. Res. 76, 6440-6454.

Johnson, L. R., T. V. McEvilly, and K. L. McLaughlin (1982). Near-field recordings of ground accelerations from the Harzer explosion, abstract, EOS 62, 971.

Lambert, D. G., E. A. Flinn, and C. B. Archambeau (1972). A comparative study of the elastic wave radiation from earthquakes and underground explosions, Geophys. J. 29, 403-432.

Langston, C. A. and D. V. Helmberger (1975). A procedure for modelling shallow dislocation sources, Geophys. J. 42, 117-130.

Minster, J. B., J. M. Savino, W. L. Rodi, T. H. Jordan, and J. F. Masso (1981). Three-dimensional velocity structure of the crust and upper mantle beneath the Nevada test site, Final Technical Report, SSS-R-81-5138, S-Cubed, La Jolla, California.

Murphy, J. R., C. B. Archambeau, and H. K. Shah (1983). Magnitude/yield variability in the western United States: Analysis of the Rulison/Gasbuggy anomaly, Final Technical Report, SSS-R-83-5978, S-Cubed, La Jolla, California.

Nuttli, O. W. (1969). Travel times and amplitudes of $S$ waves from nuclear explosions in Nevada, Bull. Seism. Soc. Am. 59, 385-398.

Oliver, J., P. Pomeroy, and M. Ewing (1960). Long-period surface waves from nuclear explosions in various environments, Science 131, 1804-1805.

Press, F. and C. Archambeau (1962). Release of tectonic strain by undergound nuclear explosions, $J$. Geophys. Res. 67, 337-343.

Taylor, S. R. (1983). Three-dimensional crust and upper mantle structure at the Nevada Test Site, $J$. Geophys. Res. 88, 2220-2232.

Springer, D. L. (1974). Secondary sources of seismic waves from underground nuclear explosions, Bull. Seism. Soc. Am. 64, 581-594.

Toksöz, M. N. and H. H. Kehrer (1972). Tectonic strain release by underground nuclear explosions and its effect on seismic discrimination, Geophys. J. 31, 141-161.

Toksöz, M. N., D. G. Harkrider, and A. Ben-Menahem (1965). Determination of source parameters by 
amplitude equalization of seismic surface waves. 2. Release of tectonic strain by underground nuclear explosions and mechanisms of earthquakes, J. Geophys. Res. 70, 907-922.

Wallace, T. C., D. V. Helmberger, and G. R. Engen (1983). Evidence of tectonic release from underground nuclear explosions in long-period $P$ waves, Bull. Seism. Soc. Am. 73, 593-613.

Wallace, T. C., D. V. Helmberger, and G. R. Engen (1984). Evidence of tectonic release from underground nuclear explosions in long-period $S$ waves (submitted for publication).

SEISMOLOGICAL LABORATORY

CALIFORNIA INSTITUTE OF TeCHNOLOGY

Pasadena, California 91125

Contribution No. 3968

Manuscript received 12 September 1983

The present address of Thorne Lay is: Department of Geological Sciences, University of Michigan, Ann Arbor, Michigan 48109. 